\section{Ni clay neoformation on montmorillonite surface}

\author{
Rainer Dähn', André Scheidegger ${ }^{1 *}$, Alain \\ Manceau $^{2}$, Michel Schlegel ${ }^{2}$, Bart Baeyens ${ }^{1}$ and \\ Michael H. Bradbury ${ }^{1}$
}

\author{
${ }^{1}$ Paul Scherrer Institut, $\mathrm{CH}$ - 5232 Villigen PSI \\ ${ }^{2}$ Environmental Geochemistry Group, LGIT - IRIGM, \\ University of Grenoble, BP53, F - 38041 Grenoble Cedex \\ 9, France \\ "andre.scheidegger@psi.ch
}

Polarized extended X-ray absorption fine structure spectroscopy (P-EXAFS) was used to study the sorption mechanism of $\mathrm{Ni}$ on the aluminous hydrous silicate montmorillonite at high ionic strength $\left(0.3 \mathrm{M} \mathrm{NaClO}_{4}\right), \mathrm{pH} 8$ and a $\mathrm{Ni}$ concentration of 0.66 $\mathrm{mM}$. Highly textured self-supporting clay films were obtained by slowly filtrating a clay suspension after a reaction time of 14 days. P-EXAFS results indicate that sorbed $\mathrm{Ni}$ has a Ni clay-like structural environment with the same crystallographic orientation as montmorillonite layers.

\section{Keywords: Sorption, Montmorillonite, Ni, P-EXAFS}

\section{Introduction}

Sorption on mineral surfaces strongly affects the fate and mobility of contaminants in the geosphere. Therefore, an atomic level understanding of sorption mechanisms of contaminants on mineral surface is of fundamental importance for maintaining environmental quality and assessing the long-term stability of waste repositories. On clay minerals several uptake mechanisms of metal ions have been proposed: Sorption on edge sites, sorption on interlayer sites (Figure 1), and the formation of lamellar nucleation phases such as neoformed layer silicates and mixed layered double hydroxides (Scheidegger et al. 1997; Schlegel et al. 1999a; Schlegel et al. 1999b; Scheinost et al. 2000).

The use of powder EXAFS to investigate the sorption mechanism of metal ions onto clay mineral is hindered by the strong overlap of scattering contributions from atoms in the octahedral and tetrahedral sheets (Figure 1). This limitation can be overcome by performing polarized EXAFS (P-EXAFS) experiments on highly oriented self-supporting clay films (Manceau et al. 1998; Manceau et al. 1999a; Schlegel et al. 1999a). In P-EXAFS the contribution of cations from the tetrahedral sheets $(\mathrm{Al}, \mathrm{Si})$ is minimised by orienting the layer $a b$ plane parallel to the electric field vector $\vec{\varepsilon}$ of the incident X-ray beam (Figure 2). Conversely, the contribution of cations from the octahedral sheet (Al and $\mathrm{Mg}$ in montmorillonite) is extinguished in the perpendicular orientation of $\overrightarrow{\boldsymbol{\varepsilon}}$.

In P-EXAFS the apparent coordination number $\left(\mathrm{CN}^{\text {exafs }}\right)$ is (Schlegel et al. 1999a):

$$
C N_{j}^{\text {exafs }}=C N_{j}^{\text {cryst }} \cdot\left[1-\frac{\left(3 \cos ^{2} \beta_{j}-1\right)\left(3 \cos ^{2} \alpha-2\right)}{2}\right]
$$



Figure 1

Sorption modes on dioctahedral aluminous clays ( $\mathrm{V}=$ vacancy) (Tsipursky et al. 1984).

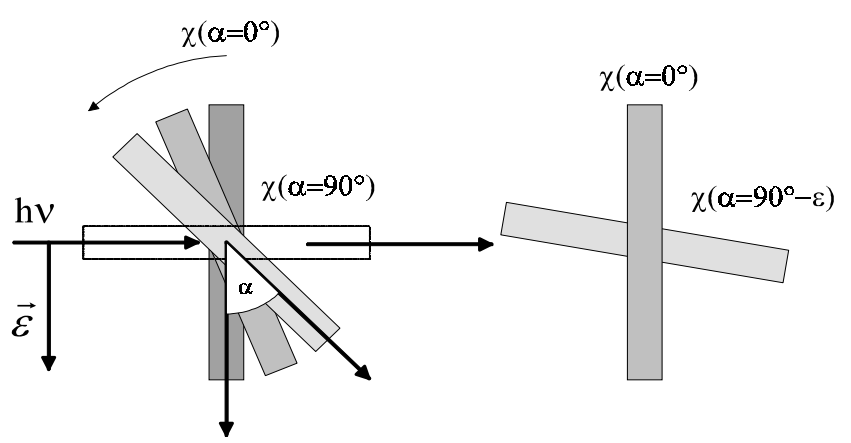

Figure 2

Orientation of the film with respect to the incoming beam. After Manceau et al. (1999a).

$\alpha=$ the angle between the electric field vector $\overrightarrow{\mathcal{E}}$ and the layer plane

$\beta=$ the angle between the film normal and the vector $\left(\mathrm{R}_{\mathrm{ij}}\right)$ that connects the absorbing atom $i$ to the backscattering atom $j$

$\mathrm{CN}^{\text {cryst }}=$ the number of atoms in the $\mathrm{j}$ shell

Equation (1) can be simplified for two "magic angles": $\mathrm{CN}^{\text {exafs }}=$ $\mathrm{CN}^{\text {cryst }}$ for $\alpha=35.3^{\circ}$ regardless $\beta$ and for $\beta=53.7^{\circ}$ regardless $\alpha$. In this study P-EXAFS was used to investigate the Ni uptake on self-supporting montmorillonite films. Dioctahedral aluminous clays are used as a backfill material in the Swiss concept for a high level radioactive waste repository and, therefore, metal sorption on montmorillonite has been investigated in our laboratory in great details (Baeyens et al. 1997).

\section{Material and Methods}

The montmorillonite STx-1 used in this study $\left(\mathrm{Si}_{4} \mathrm{Al}_{1.67}\left(\mathrm{Fe}^{2+}, \mathrm{Mg}\right)_{0.33} \mathrm{O}_{10}(\mathrm{OH})_{2}\left(\mathrm{Me}_{0.33}, \mathrm{H}_{2} \mathrm{O}\right)\right.$, where Me refers to a metal cation in the interlayer space between sheets) was purchased from the Source Clay Minerals Repository of the Clay Minerals Society. The sample was prepared by adding $200 \mathrm{ml}$ of a buffered Ni solution ( $\mathrm{pH}$ 8.0, high ionic strength of $0.3 \mathrm{M}$ $\mathrm{NaClO}_{4}$ to block cation exchange processes) to $40 \mathrm{ml}$ of a conditioned and purified montmorillonite suspension (Baeyens et al. 1997) resulting in a solid to liquid ratio of $2.14 \mathrm{~g} / \mathrm{L}$ and an initial $\mathrm{Ni}$ concentration of $0.66 \mathrm{mM}$. The preparation was performed in a glove box under $\mathrm{N}_{2}$ atmosphere $\left(\mathrm{CO}_{2}\right.$ and $\mathrm{O}_{2}<5$ 
ppm). The reaction conditions were undersaturated with respect to $\mathrm{Ni}(\mathrm{OH})_{2}$ (Mattigod et al. 1997).

After 14 days of reaction time the suspension was filtrated and a highly oriented self supporting film was prepared. The disorientation of particles off the film plane, as measured by quantitative texture analysis, is typically comprised between $10^{\circ}$ and 20 $0^{\circ}$ HWHM (Manceau et al. 1998; Manceau et al. 1999a; Schlegel et al. 1999a). Manceau et al. (2000a) showed that no significant deviation from single crystal dichroism occurs (meaning $\mathrm{CN}^{\text {exafs }} \approx \mathrm{CN}^{\text {cryst }}$ ) when the mosaic spread is less than 20-25 $5^{\circ} \mathrm{HWHM}$ for parallel measurement, and 15-20 $\mathrm{HWHM}$ for normal measurement.

The supernatant solution was analysed by ICP-MES in order to determine the amount of $\mathrm{Ni}$ sorbed onto the clay mineral. The dried clay film was cut into 8 slices and stacked on a sample holder in order to get a thick enough sample for fluorescence measurements.

Ni K-edge XAFS spectra were recorded at beamline X-11 A at the National Synchrotron Light Source, Brookhaven National Laboratory, Upton, NY using a Si (111) crystal monochromator. XAFS spectra were recorded with the electric field vector at 10 , 35,55 and 80 degrees with respect to the film plane, at RT, and by using a 13-element Ge solid state detector (Canberra).

XAFS data reduction was carried out by using the WinXAS 97 1.3 software package (Ressler 1998). Radial structure functions (RSFs) were obtained by Fourier transforming $\mathrm{k}^{3}$-weighted $\chi(\mathrm{k})$ functions between 3.2 to $10 \AA^{-1}$ using a Bessel window function with a smoothing parameter of 4 . Amplitude and phase shift functions were calculated with FEFF 8.0 (Rehr et al. 1991) using the structures of $\beta-\mathrm{Ni}(\mathrm{OH})_{2}$ and Ni-Talc (Perdikatsis et al. 1981) as references. The amplitude reduction factor $\left(\mathrm{S}_{0}{ }^{2}\right)$ was determined to 0.85 from the experimental $\beta-\mathrm{Ni}(\mathrm{OH})_{2}$ EXAFS spectrum.

\section{Results and Discussion}

Figure 3 shows a comparison between $\mathrm{k}^{3}$-weighted Ni-EXAFS spectra of a wet paste $(96 \mu \mathrm{g} / \mathrm{g} \mathrm{Ni})$ and of a self-supporting film $(111 \mu \mathrm{g} / \mathrm{g} \mathrm{Ni})$ measured at the "magic angle" $\left(\alpha=35^{\circ}\right)$. The $\mathrm{k}^{3} \chi(\mathrm{k})$ powder spectrum is very similar to the $35^{\circ} \mathrm{P}$-EXAFS spectrum demonstrating that the drying of the self-supporting clay film did not modify the overall coordination chemistry of $\mathrm{Ni}$.

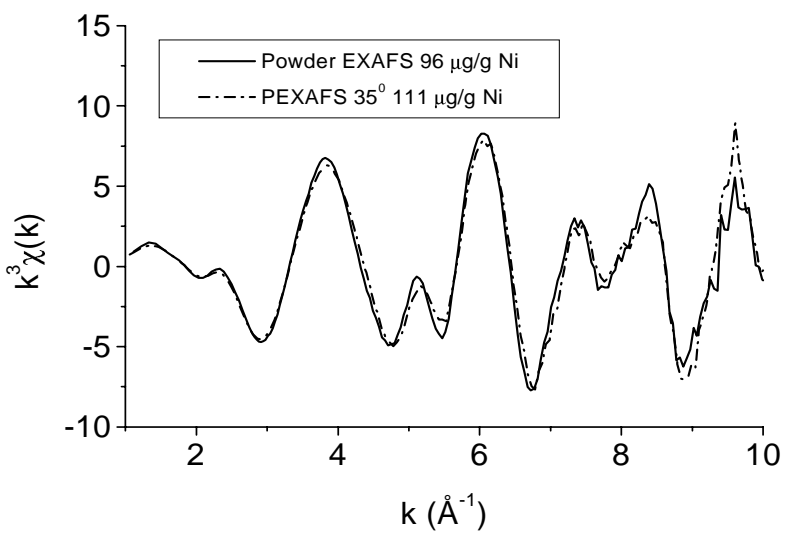

Figure 3

Comparison of $\mathrm{k}^{3}$-weighted Ni K-edge P-EXAFS spectra at $\alpha=35^{\circ}$ and powder EXAFS spectra (wet paste) for sorption samples.

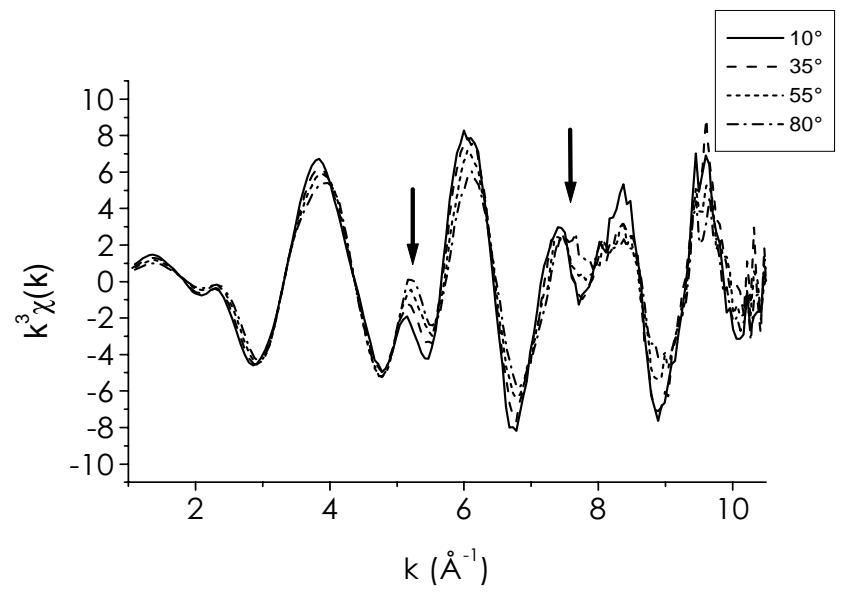

Figure 4

$\mathrm{k}^{3}$-weighted Ni K-edge EXAFS spectra at $\alpha$ angles of 10, 35, 55 and 80 degrees for Ni sorbed on montmorillonite $(111 \mu \mathrm{mol} / \mathrm{g}, \mathrm{pH}=8)$.

Figure 4 shows the angular dependence of $111 \mu \mathrm{mol} / \mathrm{g} \mathrm{Ni}$ sorbed on montmorillonite at $\mathrm{pH} 8$. With increasing $\alpha$ angle, the shoulder of $\mathrm{k}^{3} \chi(\mathrm{k})$ at $5.3 \AA^{-1}$ increases and the wave frequency at $5.3 \AA^{-1}$ and at $7.5 \AA^{-1}$ shifts. The change in frequency and the wave feature at $5.3 \AA^{-1}$ indicates that the coordination chemistry of $\mathrm{Ni}$ is anisotropic, and that its coordination spheres are oriented with respect to clay layers.

Figure 5 shows experimental and simulated RSFs. The amplitude of the first (Ni-O contribution) and second (Ni-cation contribution) peaks decreases with increasing $\alpha$ angle. The position of the second peak is shifted from $2.75 \AA$ at $\alpha=10^{\circ}$, a typical peak position for a $\mathrm{Ni}-\mathrm{Ni}$ pair in sheet silicates (Manceau et al. 1986; Scheidegger et al. 1997), to $2.8 \AA$ at $\alpha=80^{\circ}$ (distances are uncorrected for phase shift). Lastly, the imaginary part of the Fourier transform shifts to higher distance values with increasing $\alpha$ angle. Similar angular dependences were reported in ferric smectite films and were showed to correspond to the selection of the $\mathrm{Fe}-\mathrm{Fe}$ octahedral sheet contribution in the parallel orientation and of the $\mathrm{Fe}-\mathrm{Si}$ contribution in the perpendicular orientation (Manceau et al. 2000b; Manceau et al. 2000c).

In Table 1 the structural parameters derived from the fit are summarised. At $\alpha=80^{\circ}$ the second RSF peak consists of about $\mathrm{CN}^{\text {exafs }}=6.0 \pm 1.2 \mathrm{Si}$ atoms at a distance of $3.26 \AA$. In this out-ofplane direction no Ni-Ni interactions are detected. At $\alpha=10^{\circ}$ the second RSF peak consists of $\mathrm{CN}^{\text {exafs }}=3.9 \pm 0.8 \mathrm{Ni}$ atoms at 3.08 $\AA$ and $\mathrm{CN}^{\text {exafs }}=3.2 \pm 0.6 \mathrm{Si}$ atoms at $3.26 \AA$. These $\mathrm{Ni}-\mathrm{Ni}$ and $\mathrm{Ni}$ $\mathrm{Si}$ distances are characteristic of Ni clays (Manceau et al. 1986), which indicates that the sorption of $\mathrm{Ni}$ resulted in the neoformation of a nickeloan clay. Since the Ni-Ni and Ni-Si pairs have the same orientations as the $\mathrm{Al}-\mathrm{Al}$ and $\mathrm{Al}-\mathrm{Si}$ pairs in montmorillonite particles of the film, this neoformed clay is crystallographically oriented with respect to montmorillonite layers. Clay neoformation on mineral surface has been recently demonstrated in the case of cobalt on quartz (Manceau et al. 1999b) and zinc on hectorite smectite (Schlegel et al. 2000), and this mechanism could account for the immobilisation of trace elements in natural systems, such as zinc in contaminated soils (Manceau et al. 2000d). 


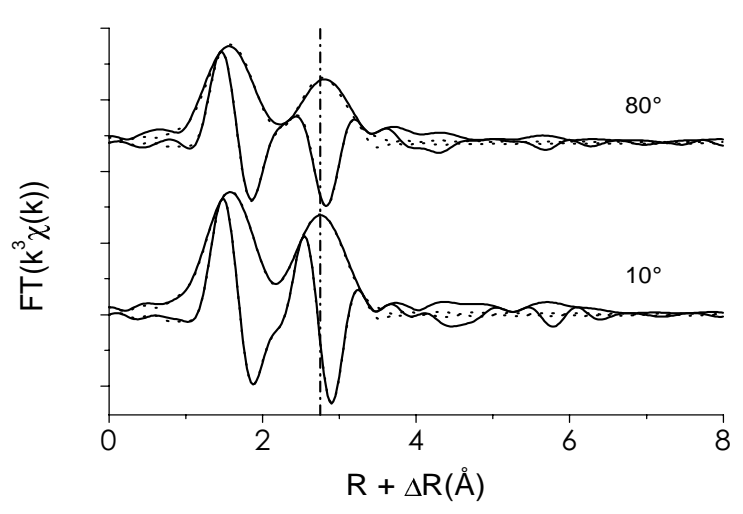

Figure 5

Polarisation dependence of Ni K-edge RSFs at $\alpha$ angles of 10 and 80 degrees for $111 \mu \mathrm{mol} / \mathrm{g} \mathrm{Ni}$ sorbed on montmorillonite at $\mathrm{pH}$ 8. The solid line represents the experimental data and the dashed line the fit.

\begin{tabular}{|c|c|c|c|c|c|c|c|c|c|c|}
\hline \multirow[b]{2}{*}{$\alpha$} & \multicolumn{3}{|c|}{$\mathrm{Ni}-\mathrm{O}$} & \multicolumn{3}{|c|}{$\mathrm{Ni}-\mathrm{Ni}$} & \multicolumn{3}{|c|}{$\mathrm{Ni}-\mathrm{Si}$} & \\
\hline & $\mathrm{CN}^{\text {exafs }}$ & $\begin{array}{c}\mathrm{R} \\
{[\AA]}\end{array}$ & $\begin{array}{c}\sigma^{2} \\
{\left[\AA^{2}\right]}\end{array}$ & $\mathrm{CN}^{\text {exafs }}$ & $\begin{array}{c}\mathrm{R}_{\mathrm{Ni}-\mathrm{Ni}} \\
{[\AA]}\end{array}$ & $\begin{array}{c}\sigma^{2} \\
{\left[\AA^{2}\right]}\end{array}$ & $\mathrm{CN}^{\text {exafs }}$ & $\begin{array}{c}\mathrm{R}_{\mathrm{Ni}-\mathrm{Si}} \\
{[\tilde{\AA}]}\end{array}$ & $\begin{array}{c}\sigma^{2} \\
{\left[\AA^{2}\right]}\end{array}$ & $\begin{array}{l}\Delta \mathrm{E}_{0} \% \text { Res } \\
{[\mathrm{eV}]}\end{array}$ \\
\hline $10^{\circ}$ & 5.7 & $2.04^{f}$ & $0.006^{f}$ & 3.9 & $3.08^{\mathrm{f}}$ & $0.008^{f}$ & 3.2 & $3.26^{\mathrm{a}}$ & $0.008^{\mathrm{a}}$ & $1.4^{\mathrm{f}} \quad 2.0$ \\
\hline $35^{\circ}$ & 5.5 & 2.04 & 0.006 & 2.5 & 3.08 & 0.008 & 4.2 & $3.26^{\mathrm{a}}$ & $0.008^{\mathrm{a}}$ & $1.4 \quad 3.2$ \\
\hline $55^{\circ}$ & 5.0 & $2.04^{f}$ & $0.006^{f}$ & 1.4 & $3.08^{\mathrm{f}}$ & $0.008^{f}$ & 5.2 & $3.26^{\mathrm{a}}$ & $0.008^{\mathrm{a}}$ & $1.4^{\mathrm{f}} \quad 3.3$ \\
\hline $80^{\circ}$ & 4.6 & $2.04^{\mathrm{f}}$ & $0.006^{\mathrm{f}}$ & & & & 6.0 & 3.26 & 0.008 & $1.4^{\mathrm{f}} \quad 6.3$ \\
\hline
\end{tabular}

Table 1: Structural Information Derived from EXAFS Analysis. $\mathrm{CN}^{\text {exafs }}, \mathrm{R}, \sigma^{2}, \Delta \mathrm{E}_{\mathrm{O}}$ are the apparent coordination numbers, interatomic distances, Debye-Waller factors and inner potential corrections a: Fixed to the value determined at $80^{\circ}$.

f: Fixed to the value determined at $35^{\circ}$.

The deviation between the fitted and the experimental spectra is given by the relative residual in percent, \% Res.

The absolute precision on $\mathrm{R}$ is estimated to $\pm 0.02 \AA$ and on $C \mathrm{CN}^{\text {exafs }}$ to $20 \%$. The relative precision on $\mathrm{CN}^{\text {exafs }}$ for different angles is about $10 \%$.

\section{Acknowledgements}

The authors thank Kaumudi Pandya (Brookhaven National Laboratory, Upton, NY) for her support during the XAFS measurements. Partial financial support was provided by the National Co-operative for the Disposal of Radioactive Waste (Nagra), Wettingen (Switzerland).

\section{References}

Baeyens, B. \& Bradbury, M. H. (1997). J. Contam. Hydrol 27: 199-222.

Manceau, A. \& Calas, G. (1986). Clay Minerals 21: 341-360.

Manceau, A., Chateigner, D. \& Gates, W. P. (1998). Phys. Chem. Minerals 25: 347-365.

Manceau, A., Schlegel, M. L., Chateigner, D., Lanson, B., Bartoli, C. \& W.P., G. (1999a). Synchrotron X-ray Methods in Clay Science. D. G. Schulze, J. W. Stucki and P. M. Bertsch, Clay Mineral Society: 68-114.
Manceau, A., Schlegel, M., Nagy, K. L. \& Charlet, L. (1999b). J. Colloid Interface Sci. 220: 181-197.

Manceau, A. \& Schlegel, M. (2000a). Physics and Chemistry of Mineral: in press.

Manceau, A., Lanson, B., Drits, V. A., Chateigner, D., W.P., G., Wu, J. \& Stucki, J. W. (2000b). American Mineralogist 85(1): 133-152.

Manceau, A., Drits, V. A., Lanson, B., Chateigner, D., Wu, J., Huo, D., W.P., G. \& Stucki, J. W. (2000c). American Mineralogist 85(1): 153-172.

Manceau, A., Lanson, B., Schlegel, M. L., Hargé, J. C., Musso, M., Eybert-Bérard, L., Hazemann, J. L., Chateigner, D. \& Lamble, G. M. (2000d). American Journal of Science 300: 289-343.

Mattigod, S. V., Rai, D., Felmy, A. R. \& Rao, L. (1997). Journal of Solution Chemistry 26(4): 391-403.

Perdikatsis, B. \& Burzlaff, H. (1981). Zeitschrift für Kristallographie 156: 177-186.

Rehr, J. J., Mustre de Leon, J., Zabinsky, S. \& Albers, R. C. (1991). Journal of the American Chemical Society 113(14): 5135-5140.

Ressler, T. (1998). Journal of Synchrotron Radiation 5(2): 118122.

Scheidegger, A. M., Lamble, G. M. \& Sparks, D. L. (1997). J. Colloid Interface Sci. 186: 118-128.

Scheinost, A. C. \& Sparks, D. L. (2000). J. Colloid Interface Sci. 223: $1-12$.

Schlegel, M., Manceau, A., Chateigner, D. \& Charlet, L. (1999a). J. Colloid Interface Sci. 215: 140-158.

Schlegel, M. L., Manceau, A. \& Charlet, L. (1999b). J. Colloid Interface Sci. 220: 392-405.

Schlegel, M. L., Manceau, A., Charlet, L. \& Hazemann, J. L. (2000). American Journal of Science: accepted pending minor revisions.

Tsipursky, S. I. \& Drits, V. A. (1984). Clay Minerals 19(2): 177193. 